\title{
Alterações de sensibilidade após a remoção de terceiros molares inferiores
}

\author{
Jorge Faber*
}

Alterações de sensibilidade dos nervos alveolar inferior e lingual podem ser complicações importantes das remoções de terceiros molares inferiores. Elas podem ocorrer em virtude de traumas diretos, tal como a incisão do nervo, ou indiretos, como o trauma por compressão de hematoma ou edema. Em qualquer situação o problema pode levar a déficits funcionais, desgastes no relacionamento cirurgião-dentista/paciente, ou mesmo à litigâncias nos tribunais. Assim, estimar a freqüência de danos temporários e permanentes a esses nervos e identificar fatores associados com as taxas de injúria são importantes para a Odontologia e constituíram os objetivos de um trabalho realizado por um grupo de cirurgiões bucomaxilofacias (CBMFs) da Califórnia ${ }^{1}$.

Questionários foram enviados a todos os CBMFs pertencentes à Associação Californiana de Cirurgiões Bucomaxilofaciais. Eles continham perguntas relativas às alterações de sensibilidade ocorridas após a remoção de terceiros molares inferiores nos últimos 12 meses anteriores ao recebimento da correspondência e se tinham conhecimento de alterações permanentes ocorridas ao longo de suas carreiras.

Os autores do trabalho receberam um número alto de respostas, pois 535 questionários foram respondidos, totalizando 95\% dos CBMFs do estado. Um total de 94,5\% dos CBMFs relatou ter casos de alteração de sensibilidade do nervo alveolar inferior em sua clínica, enquanto as alterações que afetavam o nervo lingual foram relatadas por $53 \%$ dos profissionais. Entretanto, as taxas de ocorrência pelo número de extrações foram relativamente baixas, 4 por 1.000 e 1 por 1.000 para os nervos alveolar inferior e lingual, respectivamente.

É importante ressaltar que esse estudo é retrospectivo e incluiu casos referidos espontaneamente pelos profissionais. É provável que a freqüência de danos aos nervos seja maior do que a encontrada nesse trabalho. Entretanto, os resultados mostram que a grande maioria dos profissionais enfrenta esse tipo de problema de forma recorrente.

Como em muitas situações clínicas é difícil discernir a relação das raízes dentárias com o canal mandibular (Fig. 1), uma questão importante se faz presente: o que fazer? Uma proposta para cirurgia de alguns terceiros molares inclusos é sua remoção parcial, ou coronecto$\mathrm{mia}^{2}$. Nesse caso, somente a coroa dentária é removida, ficando o remanescente radicular no interior do osso, diminuindo a manipulação da região próxima ao alveolar inferior. Outra alternativa, que talvez proporcione maior segurança na cirurgia, é a realização de prototipagem dos terceiros e segundos molares inferiores e nervo alveolar inferior. Essa metodologia é recente ${ }^{3}$ e permite avaliar as relações das estruturas anatômicas na área que será submetida à cirurgia. Alguns estudos demonstram que a utilização de prototipagem para outras cirurgias, que não as de remoção de dentes, diminui o tempo de cirurgia de $30 \%$ a $50 \%$ e torna o pós-operatório mais confortável.

Alterações de sensibilidade decorrentes da remoção de terceiros molares ocorrem em freqüência relativamente baixa e afetam grande parte dos CBMFs. Trabalhos futuros que envolvam a prototipagem da área previamente à cirurgia são hoje necessários. É possível que essa abordagem clínica traga muitos benefícios para os pacientes na remoção de terceiros molares inferiores.

1. ROBERT, R. C.; BACCHETTI, P.; POGREL, M. A. J Oral Maxillofac Surg, Philadelphia, v. 63, no. 6, p. 732-735, 2005.

2. POGREL, M. Coronectomy in lower third molar removal. J Oral Maxillofac Surg, Philadelphia, v. 61, p. 25, 2003. Suppl. 1.

3. FABER, J. Pergunte a um expert: Jorge Faber responde. R Clín Ortod Dental Press, Maringá, dez./jan. 2005. No prelo.

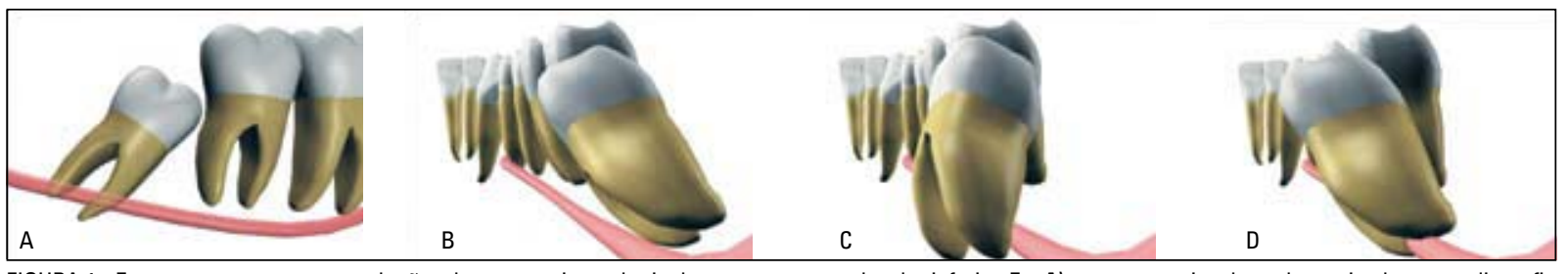

FIGURA 1 - Esquema que representa relações de um terceiro molar incluso com o nervo alveolar inferior. Em A) temos uma vista lateral que simula uma radiografia periapical dessa região. Não é possível estabelecer qual a relação da raiz do 48 com o nervo. Essa imagem poderia ser fruto de uma raiz B) por vestibular, C) lingual, D) ou mesmo de uma raiz que abraçasse o nervo.

* Doutor em Biologia - Morfologia, Laboratório de Microscopia Eletrônica da Universidade de Brasília, Mestre em Ortodontia pela

Universidade Federal do Rio de Janeiro, Clínica privada focada no atendimento de pacientes adultos. 